\title{
Reduction of Birth Weight Among Infants Born to Adolescents: Maternal-Fetal Growth Competition
}

\author{
A. ROBERTO FRISANCHO ${ }^{a}$ \\ Center for Human Growth \& Development and Department of Anthropology \\ University of Michigan \\ Ann Arbor, Michigan 48109-0406
}

\section{INTRODUCTION}

Previous investigations have indicated that the birth weights of infants born to adolescent mothers are lower than those of infants born to adult mothers. Some investigators have attributed these differences to socioeconomic factors, while others have postulated that the low birth weights of infants born to adolescent mothers are a consequence of the maternal-fetal growth competition for nutrients. ${ }^{1-3}$ Studies conducted among Peruvian adolescents found that still-growing teenagers transfer a lower proportion of their pregnancy weight gain to their fetus than do adults. ${ }^{2,3}$ Also, studies of teenagers in the United States found that young adolescents transfer a lower proportion of their pregnancy weight gain to their newborns than do older adolescents and adults. ${ }^{4-8}$ However, a recent report ${ }^{9}$ based on a study of 141 black adolescents concluded that young adolescents contributed equal or greater amounts of their gestational weight gain to their fetuses than older adolescents. Hence, it is not clear whether there is a maternal-fetal growth competition for nutrients among young adolescents. To clarify this issue we have analyzed the relationship of material weight gain to the birth weights of 9694 black and white young adolescents, older adolescents, and adults derived from the 1959-1965 National Collaborative Perinatal Project.

\section{METHODS AND MATERIALS}

\section{Sample}

This sample was selected from the datasets of the 1959-1965 National Collaborative Perinatal Project. ${ }^{10}$

\section{General Characteristics}

To establish the relationship of birth weight and pregnancy weight gain, the study included a sample of 9694 subjects ranging in age from 14 to 24 years, of which 5410 were black and 4284 were white.

${ }^{a}$ Author to whom correspondence should be addressed. Tel.: (313) 764-2443; fax: (313) 9369288; e-mail: 


\section{Pregnancy Weight-gain Trends}

To determine the pattern of pregnancy weight gain, the study included a sample of 3292 blacks and 2887 whites gravidas whose weight was measured at the seventh, eighth, and ninth month of pregnancy.

\section{Criteria for Sample Selection}

The criteria for sample selection included:

1. The adolescent mothers had the same income range as the adult controls.

2. The adolescent mothers had the same range of prepregnancy weight as the adult controls: 31 to $68 \mathrm{~kg}$ for blacks and 41 to $90 \mathrm{~kg}$ for whites.

3. Mothers smoked less than 7 cigarettes per day during pregnancy.

4. Newborns had a gestational age of 37 to 42 weeks.

5. Newborns had a birth weight that ranged from 1500 to 5600 grams.

6. Women whose weight at delivery was less than prepregnancy were excluded.

\section{Data Analysis}

Each sample was divided into three age groups: (1) 14.0 to 16.9 years; (2) 17.0 to 18.9 years; and (3) 19.0 to 24.9 years. In each age group the dependent variable was birth weight measured in grams, while pregnancy weight gain was the independent variable. For the purpose of this study weight gain was defined as the difference between prepregnancy weight and weight at delivery. Women whose weight at delivery was less than prepregnancy were excluded from the present study. The reason for this exclusion is that about $4 \%$ of the adult black women in these datasets experienced a decline in weight during pregnancy, a trend not exhibited in the adolescent samples. Since the objective of this study was to determine the role of weight gain on neonatal outcome, it would be contradictory to include those women who lost weight during pregnancy.

In order to determine the nature of the relationship between weight gain and birth weight we used regression analysis. We were thus able to derive the regression coefficient for pregnancy weight gain on birth weight. This procedure allowed us to compare the proportion of weight gain transferred from the adolescent and adult mothers to their fetuses.

\section{RESULTS}

TABLE 1 presents the general characteristics of both the black and white samples. In general, the young adolescents were significantly $(p<0.05)$ shorter than the older adolescents and adults. Similarly, despite the fact that the samples were matched for the same prepregnancy weight range, the adults were significantly heavier than the adolescents of all ages. The birth weight for the young adolescents in both black and whites was significantly less than that of older adolescents and adult samples. On the 
TABLE 1. General Characteristics of Black and White Adolescents and Adults Matched for the Prepregnancy Weight Range, Who Smoked Less than 7 Cigarettes/Day, and had Full-term Deliveries (Gestational Age 37 to 42 weeks)

\begin{tabular}{|c|c|c|c|c|}
\hline & $\begin{array}{l}\text { Younger } \\
\text { Adolescents }\end{array}$ & $\begin{array}{c}\text { Older } \\
\text { Adolescents }\end{array}$ & $\begin{array}{l}\text { Adult } \\
\text { Sample }\end{array}$ & \\
\hline $\begin{array}{l}\text { Age Range } \\
\text { (yr) }\end{array}$ & $\begin{array}{r}14.0-16.9 \\
\text { Mean } \pm \text { SD }\end{array}$ & $\begin{array}{c}17.0-18.9 \\
\text { Mean } \pm \text { SD }\end{array}$ & $\begin{array}{c}19.9-24.9 \\
\text { Mean } \pm \text { SD }\end{array}$ & F-test \\
\hline \multicolumn{5}{|c|}{ Black } \\
\hline$N$ & 798 & 1219 & 3393 & \\
\hline Age $(y r)$ & $15.4 \pm 0.7$ & $17.6 \pm 0.5$ & $21.2 \pm 1.7$ & $b$ \\
\hline Height $(\mathrm{cm})$ & $159.6 \pm 6.3$ & $160.8 \pm 6.0$ & $161.0 \pm 6.5$ & $a$ \\
\hline Prepregnancy weight $(\mathrm{kg})$ & $53.7 \pm 6.5$ & $54.7 \pm 6.5$ & $55.8 \pm 6.8$ & $a$ \\
\hline Birth weight $(\mathrm{g})$ & $3042.8 \pm 414.5$ & $3080.5 \pm 414.8$ & $3129.1 \pm 429.1$ & $b$ \\
\hline Length of gestation (weeks) & $39.6 \pm 1.5$ & $39.5 \pm 1.4$ & $39.5 \pm 1.4$ & N.S. \\
\hline $\begin{array}{l}\text { Maternal weight gain }(\mathrm{kg}) \\
\text { during gestation }\end{array}$ & $10.9 \pm 4.8$ & $10.5 \pm 4.8$ & $10.4 \pm 4.5$ & N.S. \\
\hline $\begin{array}{l}\text { Ratio of birthweight to } \\
\text { pregnancy weight gain }(\%)\end{array}$ & $34.7 \pm 12.8$ & $37.4 \pm 28.5$ & $36.5 \pm 26.4$ & $a$ \\
\hline \multicolumn{5}{|c|}{ White } \\
\hline$N$ & 155 & 610 & 3519 & \\
\hline Age (yr) & $15.6 \pm 0.6$ & $17.6 \pm 0.5$ & $21.5 \pm 1.6$ & $b$ \\
\hline Height $(\mathrm{cm})$ & $160.0 \pm 6.1$ & $161.0 \pm 6.4$ & $162.0 \pm 6.5$ & $a$ \\
\hline Prepregnancy weight $(\mathrm{kg})$ & $54.5 \pm 7.0$ & $54.8 \pm 7.5$ & $57.1 \pm 8.3$ & $a$ \\
\hline Birth weight $(\mathrm{g})$ & $3302.6 \pm 483.0$ & $3355.4 \pm 434.0$ & $3994.1 \pm 450.0$ & $b$ \\
\hline Length of gestation (weeks) & $40.0 \pm 1.6$ & $40.0 \pm 1.4$ & $40.0 \pm 1.3$ & N.S \\
\hline $\begin{array}{l}\text { Maternal weight gain }(\mathrm{kg}) \\
\text { during gestation }\end{array}$ & $11.9 \pm 4.8$ & $11.3 \pm 4.4$ & $10.4 \pm 4.2$ & $a$ \\
\hline $\begin{array}{l}\text { Ratio of birthweight to } \\
\text { pregnancy weight gain (\%) }\end{array}$ & $31.8 \pm 12.8$ & $34.1 \pm 20.5$ & $38.2 \pm 26.8$ & $b$ \\
\hline
\end{tabular}

Data from the National Collaborative Perinatal Project (NCPP).

${ }^{a}$ Significantly $(p<0.05)$ different from younger adolescents.

${ }^{b}$ Significantly $(p<0.01)$ different from younger adolescents.

other hand, the cumulative pregnancy weight gains by month in the final trimester (TABLE 2) of the young adolescents was equal to or greater than those of older adolescents and adults. As a consequence of these trends, the ratio of birth weight to pregnancy weight gain in both black and white adolescents is significantly $(p<0.05)$ smaller than that of adults ( 34.7 vs. 37.0 for blacks, and 31.8 vs. 38.2 for whites).

As shown in the regression analysis presented in TABLE 3 , the regression coefficient (slopes) of pregnancy weight gain and birth weight in the young adolescents is significantly $(p<0.01)$ smaller $(21.6 \mathrm{~g} / \mathrm{kg}$ of weight gain for blacks, and $20.0 \mathrm{~g} / \mathrm{kg}$ of weight gain for whites) than in the older adolescents $(23.3 \mathrm{~g} / \mathrm{kg}$ weight gain for blacks, and $23.5 \mathrm{~g} / \mathrm{kg}$ weight gain for whites), or adults $(24.5 \mathrm{~g} / \mathrm{kg}$ weight gain for blacks, and $25.0 \mathrm{~g} / \mathrm{kg}$ weight gain for whites). Therefore, as illustrated in FIGUREs 1 
TABLE 2. Cumulative Gain by Month (Final Trimester of Pregnancy) of Black and White Adolescents and Adults Matched for Prepregnancy Weight Range, Who Smoked Less than 7 Cigarettes/Day and had Full-term Deliveries (Gestational Age 37 to 42 weeks)

\begin{tabular}{|c|c|c|c|c|c|c|}
\hline \multirow{3}{*}{$\begin{array}{l}\text { Age Range } \\
\text { (yr) }\end{array}$} & \multicolumn{2}{|c|}{ Younger Adolescents } & \multicolumn{2}{|c|}{ Older Adolescents } & \multicolumn{2}{|c|}{ Adult Sample } \\
\hline & \multicolumn{2}{|c|}{$14.0-16.9$} & \multicolumn{2}{|c|}{$17.0-18.9$} & \multicolumn{2}{|c|}{$19.9-24.9$} \\
\hline & $N$ & Mean \pm SD & $N$ & Mean \pm SD & $N$ & Mean \pm SD \\
\hline \multicolumn{7}{|c|}{ Black } \\
\hline 7 th month & 482 & $7.4 \pm 3.5$ & 751 & $7.4 \pm 3.6$ & 2059 & $7.4 \pm 3.6$ \\
\hline 8th month & 482 & $8.9 \pm 3.8$ & 751 & $8.9 \pm 3.8$ & 2059 & $8.8 \pm 3.8$ \\
\hline Delivery & 482 & $10.7 \pm 4.2$ & 751 & $10.4 \pm 4.1$ & 2059 & $10.2 \pm 4.1^{a}$ \\
\hline \multicolumn{7}{|c|}{ White } \\
\hline 7th month & 103 & $8.3 \pm 3.98$ & 380 & $7.6 \pm 3.3$ & 2404 & $7.3 \pm 3.21$ \\
\hline 8th month & 103 & $10.0 \pm 4.0$ & 380 & $9.2 \pm 3.3$ & 2404 & $8.6 \pm 3.3^{a}$ \\
\hline Delivery & 103 & $11.4 \pm 4.3$ & 380 & $10.7 \pm 3.7$ & 2404 & $9.9 \pm 3.9^{a}$ \\
\hline
\end{tabular}

Data from the National Collaborative Perinatal Project (NCPP).

${ }^{a}$ Significantly $(p<0.05)$ different from younger adolescents.

TaBle 3. Regression Analysis of Pregnancy Weight Gain on Birth Weight among Black and White Adolescents and Adults Matched for Prepregnancy Weight Range, Who Smoked Less than 7 Cigarettes/Day and had Full-term Deliveries (Gestational Age 37 to 42 weeks)

\begin{tabular}{lccc}
\hline & Younger Adolescents & Older Adolescents & Adult Sample \\
\cline { 2 - 4 } Age Range (yr) & $14.0-16.9$ & $17.0-18.9$ & $19.9-24.9$ \\
\hline & Black & & \\
\hline$N$ & 798 & 1219 & 3393 \\
Birth weight (g) & $3032.5 \pm 14.5$ & $3080.1 \pm 11.7$ & $3131.6 \pm 7.1$ \\
$\quad$ adjusted for wt. gain & & & \\
Regression equation constant & 2817.9 & 2844.0 & 2876.8 \\
Regression coefficient & 21.3 & 23.2 & 25.1 \\
S.E. & 405.5 & 400.1 & 414.1 \\
Significance & $p<0.01$ & $p<0.01$ & $p<0.01$ \\
\hline & White & & \\
\hline$N$ & 155 & 610 & 3597 \\
Birth weight (g) & & & $3400.0 \pm 7.4$ \\
$\quad$ adjusted for wt. gain & $3263.6 \pm 35.2$ & 3331.5 & \\
Regression equation constant & 3040.2 & 3092.7 & 3135.1 \\
Regression coefficient & 22.3 & 23.5 & 25.9 \\
S.E. & 472.7 & 428.1 & 436.7 \\
Significance & $p<0.01$ & $p<0.01$ & $p<0.01$ \\
\hline
\end{tabular}

Data from the National Collaborative Perinatal Project (NCPP). 


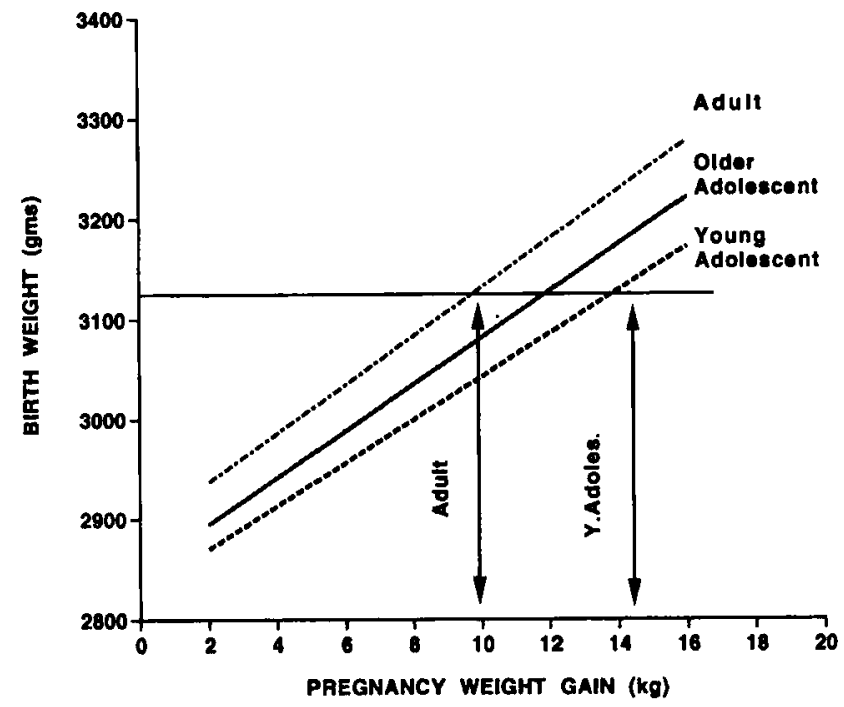

FIGURE 1. Relationship of pregnancy weight gain to newborn weight in blacks. Note that young adolescent mothers, even though they had equal or greater pregnancy weight gain, had infants that were smaller than those born to older adolescents.

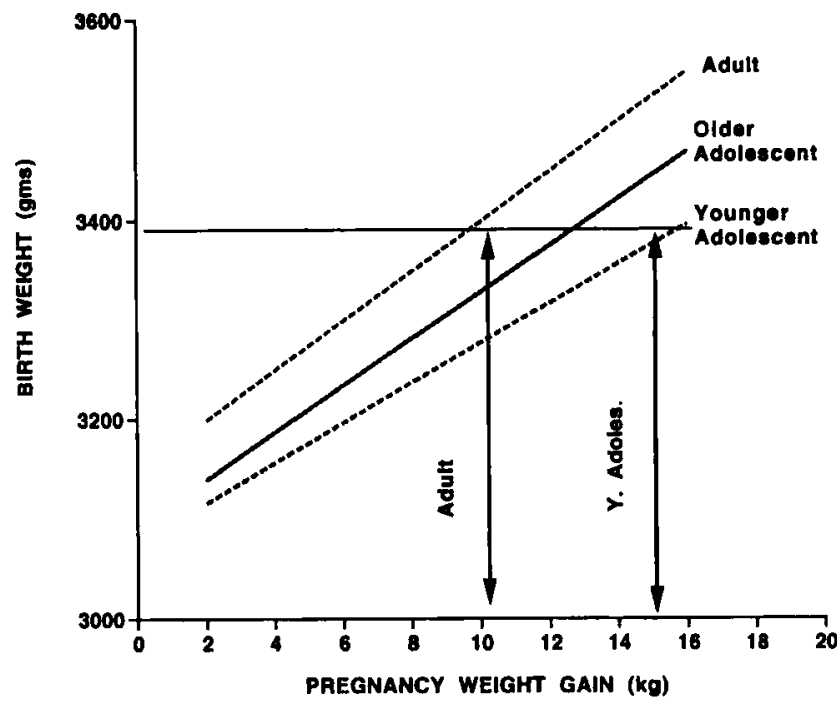

FIGURE 2. Relationship of pregnancy weight gain to newborn weight in whites. Note that young adolescent mothers, even though they had equal or greater pregnancy weight gain, had infants that were smaller than those born to older adolescents. 
and 2 , the pregnancy weight gain associated with the average birth weight $(3100$ grams for blacks, and 3400 grams for whites) is $10 \mathrm{~kg}$ for adults. In contrast, for young adolescents the pregnancy weight gain associated with the average birth weight equals about $15 \mathrm{~kg}$ for blacks and $16 \mathrm{~kg}$ for whites.

\section{DISCUSSION}

The present data suggest that young adolescents transfer a significantly smaller proportion of their pregnancy weight gain to their fetuses than do older adolescents and adults. We postulate that the lower birth weights of infants born to young adolescents are related to a maternal-fetal growth competition for nutrients. This hypothesis assumes that even though adolescents are able to reproduce, they have not completed their growth and therefore, when pregnant, compete for nutrients with their unborn fetus. We first tested this hypothesis by evaluating the relationship between

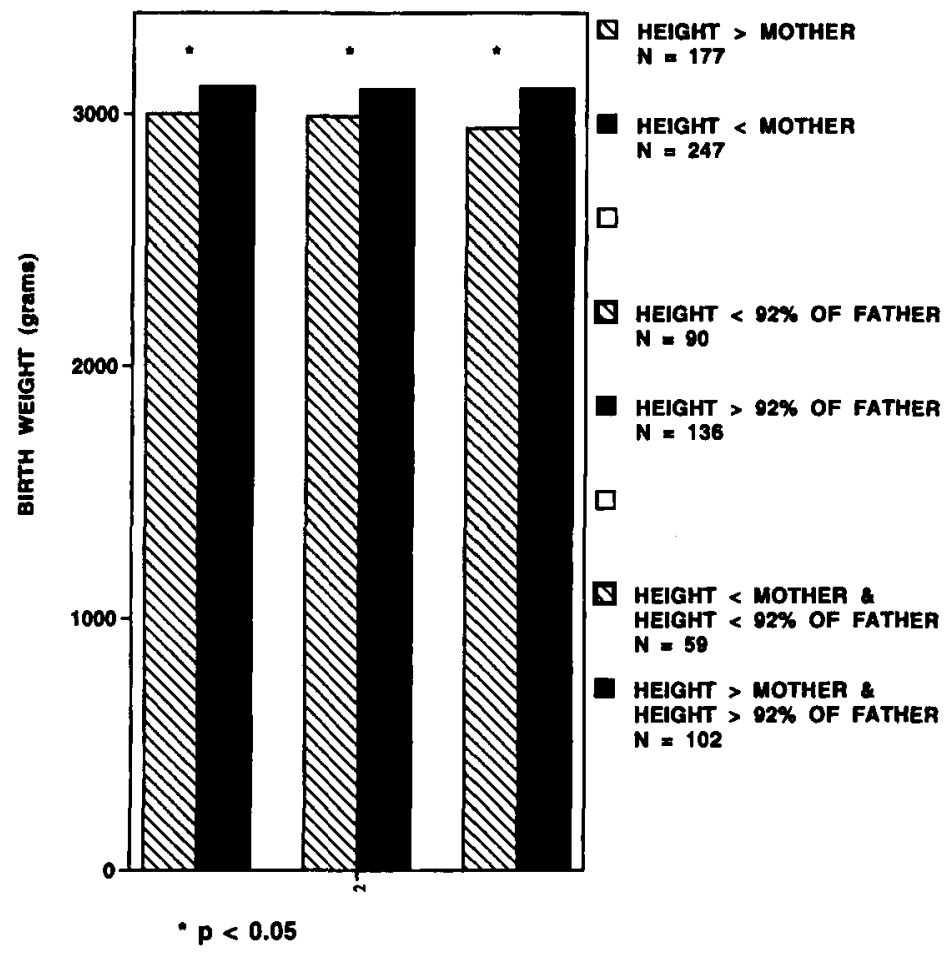

FIGURE 3. Comparison of birth weight of infants born to Peruvian adolescent mothers 13 to 15 years old who have either completed or not completed their expected growth in height. Note that those teenagers who, at the time of delivery, were "still growing" had significantly smaller newborns than their counterparts who had "completed" their expected growth. (Adapted from Frisancho et al. ${ }^{3}$ ) 
birth weight and growth status among Peruvian adolescents..$^{1-3}$ Growth status was defined using the height of the adolescent's parents as reference. Adolescents whose height was greater than their mother's height and/or greater than $92 \%$ of their father's height were considered as having "completed" their expected growth. Conversely, those whose heights were less than the mother's and/or less than $92 \%$ of the father's height were classified as still growing. As shown in FIGURE 3, the young adolescents who are "still growing" had significantly smaller newborns than their counterparts who had "completed" their expected growth. This hypothesis is illustrated in schematic form in FIGURE 4.

It has usually been assumed that after menarche girls have completed their growth in height. However, as shown in FIGURE 5, growth in stature can continue for almost 5 years after menarche, with an average increase in stature of $7.9 \mathrm{~cm}(3.1 \mathrm{in}$.) during this time. ${ }^{11}$ Furthermore, in this study increments in stature were inversely related to age at menarche, so that the earlier the age at menarche, the greater the postmenarcheal growth. " Since young age at menarche may be related to young age at first conception, one would predict that postpregnancy growth would be considerable among the young adolescent mothers. These factors support the hypothesis that teenagers, even though they are able to reproduce, probably have not completed their growth and, when pregnant, compete with their fetus for nutrients, resulting in a reduction in the birth weight of the offspring. The majority of recent studies of adolescent gravidas conducted in the United States support the maternal-fetal growth competition hypothesis. ${ }^{4-8}$ These studies demonstrated that young teenagers, despite an apparently sufficient weight gain and accumulation of abundant fat stores during pregnancy, transferred a lower proportion of their nutrient stores to the fetus than did

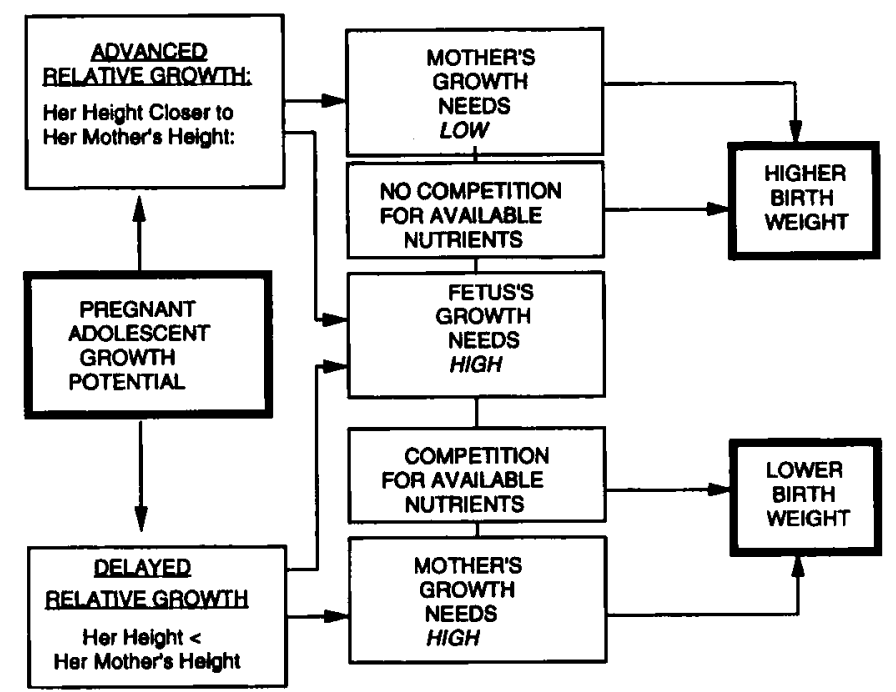

FIGURE 4. The interaction of adolescent growth status, physiological maturity, and fetal growth needs. (Adapted from Frisancho et al. ${ }^{3}$ ) 


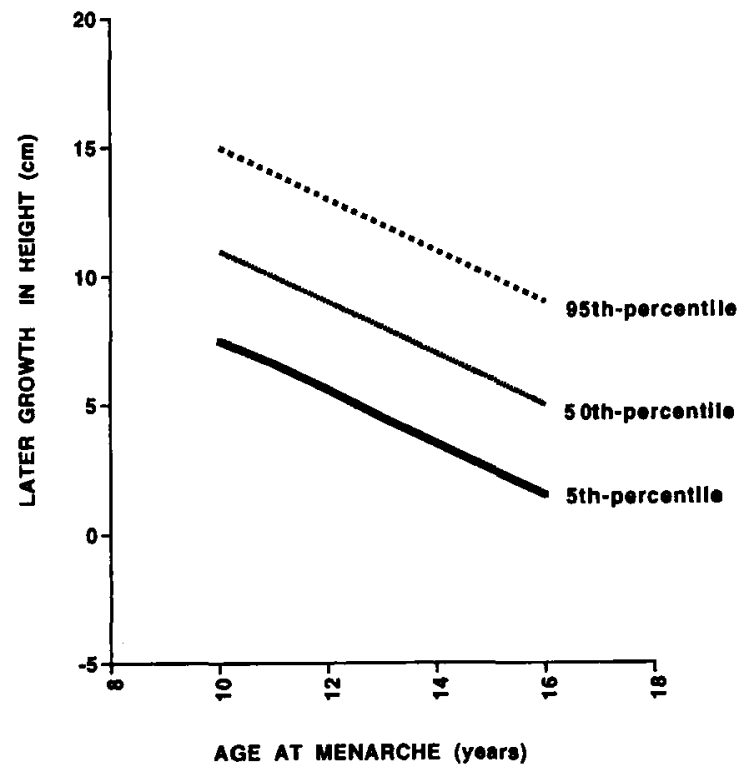

FIGURE 5. Postmenarcheal growth in height among white girls. Note that growth in stature continues for more than five years after menarche. (Adapted from Roche. ${ }^{11}$ )

adults. ${ }^{4-8}$ Furthermore, these studies ${ }^{4-7}$ demonstrate that, following the pregnancyinduced reduction in height, young adolescents do continue growing for another 4 to 5 years after delivery. It is quite possible that the continuing postpartum growth is related to the increased circulation of growth hormones and insulin resistance that characterizes pregnancy.

\section{REFERENCES}

1. NAEYE, R. L. 1981. Teenaged and pre-teenaged pregnancies: Consequences of the fetalmaternal competition for nutrients. Pediatrics 67: 146-150.

2. Frisancho, A. R., J. Matos \& P. Flegel. 1983. Maternal nutritional status and adolescent pregnancy outcome. Am. J. Clin. Nutr. 137: 739-746.

3. Frisancho, A. R., J. Matos, W. R. Leonard \& L. Yaroch. 1985. Developmental and nutritional determinants of pregnancy outcome among teenagers. Am. J. Phys. Anthropol. 66: 247-261.

4. Scholl, T. O., M. L. Hediger, C. E. Cronk \& J. I. Shall. 1993. Maternal growth during pregnancy and lactation. Horm. Res. 39(Suppl. 3): 59-67.

5. Scholl, T. O., M. L. Hediger, J. I. Schall, C. Khoo \& R. L. Fischer. 1994. Maternal growth during pregnancy and the competition for nutrients. Am. J. Clin. Nutr. 60: $183-188$.

6. Hediger, M. L., T. O. Scholl, D. H. Belsky, I. G. Ances \& R. W. Salmon. 1989. Patterns of weight gain in adolescent pregnancy: Effects on birth weight and preterm delivery. Obstet. Gynecol. 74: 6-12. 
7. Hediger, M. L., T. O. Scholl, I. G. Ances, D. H. Belsky \& R. W. Salmon. 1990. Rate and amount of weight gain during adolescent pregnancy: Associations with maternal weightfor-height and birth weight. Am. J. Clin. Nutr. 52: 793-799.

8. Rees, J. M., K. A. Engeldert-Fenton, E. J. Gong \& C. M. BaCh. 1992. Weight gain in adolescents during pregnancy: Rate related to birth-weight outcome. Am. J. Clin. Nutr. 56: $868-873$.

9. Stevens-Simon, C., E. R. McAnarney \& K. J. Roghmann. 1993. Adolescent gestational weight gain and birth weight. Pediatrics 92: 805-809.

10. Garn, S. M. \& A. S. Petzold. 1983. Characteristics of the mother and child in teenage pregnancy. AJDC 137: 365-368.

11. Roche, A. F. 1992. Growth, Maturation and Body Composition. The Fels Longitudinal Study 1929-1991. Cambridge Univ. Press. Cambridge, Mass. 